\title{
Gallbladder Kinetics: Correlation between Gall Bladder Emptying in Patients With and Without Cholelithiasis by Ultrasonography
}

\author{
Jaiswal $\mathbf{P}^{1}$, Sharma $\mathbf{P}^{2}$, Shrestha $\mathrm{DM}^{3}$, Pradhan $\mathrm{S}^{4}$
}

${ }^{1}$ Department of Radiology, Patan Hospital, Kathmandu, ${ }^{2}$ Department of Radiology, Manipal Medical College, Pokhara, ${ }^{3}$ Department of Radiology, Kathmandu Medical College, Sinamangal, Kathmandu, ${ }^{4}$ Department of Radiology, TU Teaching Hospital, Kathmandu.

\begin{abstract}
Background: Gallstone disease or cholelithiasis, is one of the most common surgical problems worldwide. The assessment of gallbladder kinetics in patients with cholelithiasis as well as in patients with high risk for cholelithiasis could play a significant role in better management and is recommended as a routine workup of biliary system in these patients. Objectives: This study was carried out to establish the relationship between impaired gall bladder emptying and gall bladder stones. It also aimed at finding out correlation between chosen risk factors. Materials and Methods: Eighty six subjects with cholelithiasis and 35 controls (without cholelithiasis) were studied. Pre-prandial gall bladder volume was measured after 6 hours of fasting, gallbladder emptying was stimulated by fatty meals of 610 and $740 \mathrm{Kcal}$ and post-prandial gallbladder volume was measured after a period of two hours with ultrasound. The difference of pre-prandial and postprandial gall bladder volume was calculated. Results: Gallbladder emptying was significantly more $(\mathrm{p}<0.001)$ in the control group than in the group of subjects with cholelithiasis. In the case group the mean difference of volume was $9.2 \pm 7.1 \mathrm{cc}$. While in control group the mean difference of volume was 17.6 \pm 14.3 . The prevalence of cholelithiasis was significantly high in females between 26- 35 years of age group and in patients with nonalcoholic fatty liver disease and in patients who had first degree relative with gall stone. Incidence of silent gall stone was also statistically significant. Conclusion: Impaired gallbladder emptying was found to be strongly associated with gall stones.
\end{abstract}

Keywords: Cholelithiasis, Gallbladder emptying, Ultrasound

\section{Introduction}

Cholelithiasis is a common surgical problem worldwide. Internationally estimated prevalence of cholelithiasis is affected by many factors including ethnicity, gender and genetics. In the United States, about 20 million people (10-20\% of adults) have gallstones. ${ }^{1}$ As real-time ultrasonography is a cheap, noninvasive, relatively easy, validated and reproducible technique, it can be repeated over time to document timerelated changes of gallbladder motor function. ${ }^{2}$ Impaired emptying in gall stone disease may be an essential factor in cholelithiasis and could thereby contribute to bile retention, which facilitates gall stone growth. $^{3}$ The assessment of gallbladder kinetics in patients with cholelithiasis

Correspondence to: Dr. Prakash Sharma, MD Department of Radiology and Imaging Manipal Teaching Hospital, Pokhara,Nepal E mail: prakashshrm@yahoo.com 
as well as in patients with high risk for cholelithiasis plays a significant role in better management. Thus this work is hoped to further strengthen the role of evaluation of gallbladder kinetics.

\section{Materials and methods}

It was a prospective study carried out in the department of Radiology and Imaging TU Teaching Hospital, Kathmandu for the period of one year. Patients with clinical findings suspicious of cholelithiasis irrespective of aetiology were subjected to ultrasound of abdomen, subjects with sonological evidence of cholelithiasis were only included in the case group. Initially 100 cases were included in this study but 14 patients could not fulfill the criteria required for the study so they were excluded. Out of 14 patients 7 patients had cholecystitis associated with cholelithiasis , 3 patients had gall bladder mass associated with cholelithiasis, 2 patients refused to eat fatty meal and another 2 patients did not turn up for the post prandial examination. So finally gall bladder motility was studied in 86 patients with gall stone and 35 control patients. Of the 86 cases 56 cases were referred from out patient department and 30 cases were referred from emergency department. Control group was obtained from general health checkup patients referred from family medicine department.

The examination was explained in detail to all the patients. Written consent was obtained. All the patients were examined with sonographic unit SONOACE 8000 LIVE with 3.5, $5 \mathrm{MHZ}$ convex transducer in supine and left lateral position with arm of the examining side raised and medially rotated.

Gallbladder volume was obtained by using the formula ${ }^{4}$

$$
\mathrm{V}=0.52 \text { (length } \mathrm{x} \text { width } \mathrm{x} \text { height) }
$$

- Length was measured in longitudinal scan from fundus to neck of gallbladder.
- Height was measured in longitudinal scan at the level of fundus of gall bladder and the maximum diameter was taken.

- Width was measured in transverse scan at maximum diameter of the gall bladder lumen.

Gallbladder volume (cc) was measured with ultrasound after 6 hours of fasting and then Gallbladder emptying was stimulated by fatty meals of 610 and $740 \mathrm{Kcal}$ (solid meal), post prandial volume was measured with ultrasound after a period of two hours. Preprandial and postprandial volume difference was calculated. The above data was collected and finally, standard statistical method ( $\mathrm{Z}$ test) was used to test the significance of the result. For analysis, standard scientific calculator and computer software (SPSS program 10) were used. A p value of $<0.05$ was considered statistically significant.

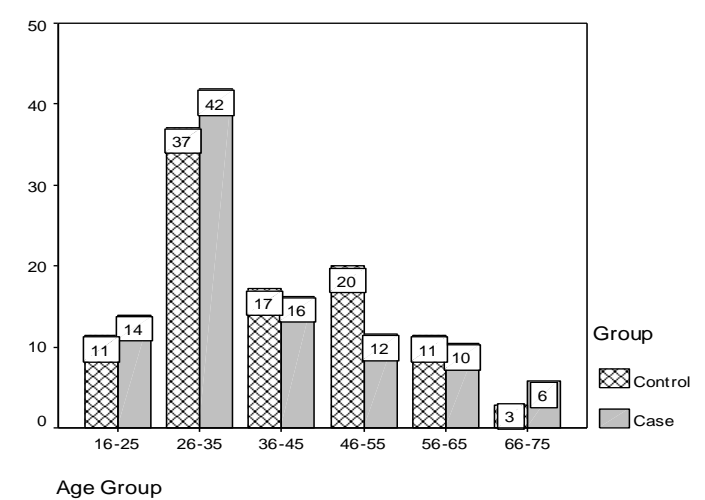

Fig 1: Distribution of cases and control according to age group

\section{Results}

The study compromised of 86 cases, out of which $56(59.5 \%)$ were female patients and $30(40.5 \%)$ were male patients. Control group compromised 35 patients, out of which $19(54.2 \%)$ were male patients and 16 $(45.7 \%)$ were female patients.

The largest age group was between 26- 35 years of age and smallest age group was between 66- 75 years of age. In case group $36(42 \%)$ patients fell in to $26-35$ years of 
age while in control group $13(37 \%)$ patients fell in to 26-35 years of age (Fig 1).

In case group $45(52.3 \%)$ patients had first degree relatives with gall stones compared to $13(37.1 \%)$ patients in the control group which was statistically significant with $\mathrm{p}<$ 0.017(Table 1).

A significant number of patients $(\mathrm{p}<0.010)$ in the case group were asymptomatic, gall stones were found incidentally during ultrasonography (Table 2).

There were altogether $39(45 \%)$ patients who had fatty liver disease and out of that 20 (24\%) patients were non alcoholic in case group.

Table 1: Frequency of family history with gall stones

\begin{tabular}{llll}
\hline Group & & Frequency & Percent \\
\hline Control & No & 22 & $62.9 \%$ \\
& Yes & 13 & $37.1 \%$ \\
Case & No & 41 & $47.7 \%$ \\
& Yes & 45 & $52.3 \%$ \\
\hline
\end{tabular}

Maximum and minimum volume difference between preprandial and postprandial volume was $26.34 \mathrm{cc}$ and $0.16 \mathrm{cc}$ respectively in the case group. While in control group maximum and minimum volume difference between preprandial and postprandial volume was $58.40 \mathrm{cc}$ and 0.94 cc respectively. There was a significant difference in mean volume difference between case and control group $(p<0.001)$. Mean volume difference in case group was $9.28 \pm 7.10 \mathrm{cc}$ and mean volume difference in control group was $17.64 \pm 14.35 \mathrm{cc}$ (Table $3)$.

Table 2: Frequency of symptoms in casegroup

\begin{tabular}{lll}
\hline Symptoms & Frequency & Percentage \\
\hline No & 34 & $39.5 \%$ \\
Yes & 52 & $60.5 \%$ \\
Total & 86 & $100 \%$ \\
\hline
\end{tabular}

\section{Discussion}

A total of 86 case and 35 healthy volunteers comprised the study group. The prevalence rate was high in females between 26 to 35 years of age group. These findings were similar to a study carried out by Jorgensen $\mathrm{T}$ in Denmark. ${ }^{5}$ It is postulated that estrogen causes increased cholesterol secretion and

Table 3: Comparison of pre and post prandial volume difference between case and control group

\begin{tabular}{lllllll}
\hline Group & & N & Minimum & Maximum & Mean & P value \\
\hline Control & Volume & 35 & 0.94 & 58.40 & $17.6 \pm 14.3$ & \\
& Difference & & & & & \\
& & & & & & \\
\hline Case & Volume & 86 & $\mathbf{0 . 1 6}$ & $\mathbf{2 6 . 3 4}$ & $\mathbf{9 . 2 \pm 7 . 1}$ & $<0.001$ \\
& Difference & & & & & \\
\hline
\end{tabular}


progesterone promotes biliary stasis. ${ }^{6}$ These factors explain the higher prevalence in female.

In our study the prevalence of gall stones was significantly higher in the first degree relatives of subjects with gallstones than that in the first degree relatives of subjects with no gallstones. In the study by Attili $\mathrm{AF}^{7}$ had found the same result. Familial clustering of cholelithiasis implies that genetic factors influence the risk of gallstone formation. Recently, twin, family, and linkage studies confirmed a genetic predisposition to the development of symptomatic gallstones. ${ }^{8}$

A significant number of our patients (39.5\%) with cholelithiasis were asymptomatic. This was higher than in Malaysian patients. ${ }^{9}$ Hypotheses could be the slow growth of stones in our population, as $80 \%$ of the asymptomatic stones were $10 \mathrm{~mm}$ or less in size. Other possibility could be asymptomatic stone may be pigment stone causing fewer symptoms. However chemical analysis of the calculi was not done in our study.

Non-alcoholic fatty liver disease (NAFLD) was found to be a significant risk factor for gall stone disease. These findings supports the similar findings found in a study carried out by P Loria at al. ${ }^{10}$ NAFLD is the hepatic manifestation of metabolic syndrome. Raised total cholesterol and apolipoprotein B (apo-B) serum concentrations and higher prevalence of hypertriglyceridemia in NAFLD could be associated with higher incidence of gall stone. ${ }^{11}$

There was a significant difference in mean volume difference between preprandial and postprandial volume in case and control group .This suggests that that hypomotility of gall bladder was strongly associated in patients with cholelithiasis. In several other studies ${ }^{3,12,13}$ similar results were obtained. Impaired emptying in gall stone disease may be an essential factor in cholelithiasis and could thereby contribute to bile retention, which facilitates gall stone growth.

Further follow up of cholelithiasis patient till surgery and chemical analysis of the calculi was not done which were the limitations of our study.

It is recommended that longer study from a more representable population covering wider geographical area, preferably in the community with chemical analysis of the calculi could reinforce or remodulated the true picture of this condition.

\section{Conclusion}

In conclusion, impaired gallbladder emptying was strongly associated with gall bladder stone. Female sex, first degree relatives with gall stones, and nonalcoholic fatty liver disease were some of the important risk factors associated with gall stones.

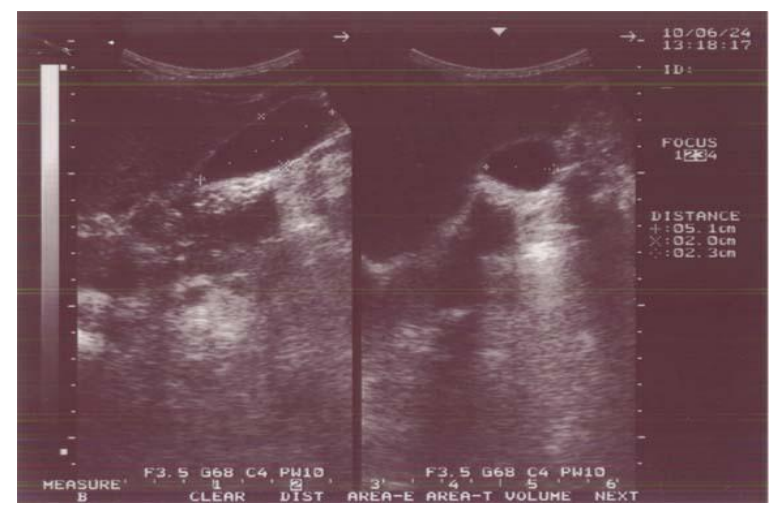

Fig 2: Gallbladder volume measurement in control

group

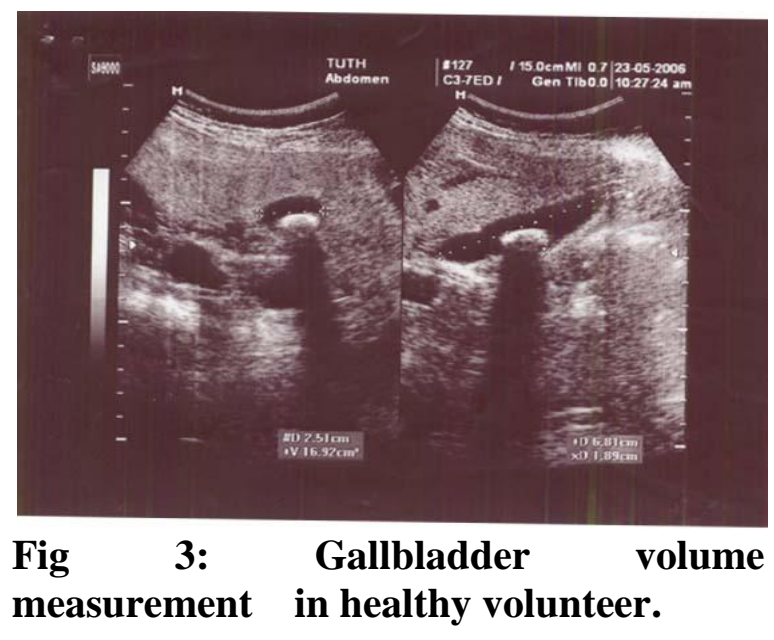




\section{References}

1. Chiang WK, Lee MF. Cholelithiasis. eMedicine website. Available at: http://emedicine.medscape.com/articl e/774352-overview. Accessed Sep 10, 2009.

2. Portincasa P, Moschetta A, Colecchia A, Festi D, Palasciano G. Measurements of gallbladder motor function by ultrasonography: towards standardization. Dig Liver Dis 2003 (suppl);35:56-61.

3. Nko'o Amvene S, Dehayem YM, Mbo Amvene J, Zo'o MR, Amana JP, Biwole SM et al . Gallbladder kinetics in the black African subject with and without cholelithiasis. An ultrasonographic study. J Radiol 2004;85(1):37-42.

4. Laing FC. Gallbladder and Bile ducts.In:Ramack CM, Wilson SR, Charboneau JW,editors.Diagnostic Ultrasound. $2^{\text {nd }}$ ed. St. Louis: Mosby, 1998:175-217.

5. Jorgensen T. Gall stones in a Danish population: fertility period, pregnancies, and exogenous female sex hormones. Gut 1988;29(4):433439.

6. Heuman DM, Mihas AA. Cholelithiasis. emedicine website. Available at: http://emedicine. medscape.com/ article/175667overview. Accessed Sep 10,2009.

7. Attili AF, De Santis A, Attili F, Roda E, Festi D, Carulli N . Prevalence of gallstone disease in first-degree relatives of patients with cholelithiasis. World J Gastroenterol 2005;11(41):6508-6511.

8. Winttenburg H, Lammert F. Genetic predisposition to gallbladder stones. Semin Liver Dis 2007;7:109-121.

9. Ross IN, Jayakumar CR. Asymptomatic Cholelithiasis and the incidence of gallstone disease. Singapore Med J 1987;28(4):314317.

10. Loria $\mathrm{P}$,Lonardo A, Lombardini S, Carulli L, Verrone A, Ganazzi D, et al. Gallstone disease in non-alcoholic fatty liver: prevalence and associated factors. J Gastroenterol Hepatol 2005;20(8):1176-1178.

11. Younossi ZM. Review article: current management of non-alcoholic fatty liver disease and non-alcoholic steatohepatitis. Aliment Pharmacol Ther2008;28(1):2-12.

12. Schafmayer A, Pauletzki J, Cicala M, Holl J .Correlation between gall bladder fasting volume and postprandial emptying in patients with gall stones and healthy controls. Gut 1993;34 (10):1443-1447.

13. Kishk SM , Darweesh RM, Dodds WJ, Lawson TL, Stewart ET, Kern MK, et al. Sonographic evaluation of resting gallbladder volume and postprandial emptying in patients with gallstones. AJR Am J Roentgenol 1987;148(5):875-879. 